\title{
Transformation process observations of polar firn to ice
}

\author{
Chester C. Langway, JR, \\ Ice Core Laboratory, State University of New York at Buffalo, Buffalo, NY 14260, U.S.A. \\ Hitoshi Shoji, Atau Mitani, \\ Snow and Ice Laboratory, Department of Earth Sciences, Toyama University, Toyama 930, Japan \\ HENRik B. ClaUSEN \\ Department of Glaciology, Geophysical Institute, University of Copenhagen, Copenhagen, Denmark
}

\begin{abstract}
The transformation of snow to ice under compressive stress is a very slow process unless meltwater is present. A qualitative measure of permeability variation with depth was continuously determined for various shallow-ice cores from the dry-snow zones in both Greenland and Antarctica to investigate this transformation process. Results of the study provide insight into snow densification mechanisms and generally characterize the pore close-off phenomena. Measurements show that bulk densities may be expressed as a function of overburden; pore close-off takes place when the overburden is approximately $3.0-4.5 \mathrm{bar}$.
\end{abstract}

\section{INTRODUCTION}

The compaction of snow to ice under compressive stress is a delayed, time-dependent process when meltwater is not present. Snow can easily be compacted to a density of about $0.55 \mathrm{~g} \mathrm{~cm}^{-3}$ even in a polar dry-snow environment, but further densification requires plastic deformation of ice grains. The transformation of snow and firn to ice is defined by the acquisition of a "zero permeability" and takes place at a density of about $0.8 \mathrm{~g} \mathrm{~cm}^{-3}$. However, the lack of any detailed observations or measurements associated with the transformational process prevents quantified interpretation in terms of snow densification mechanisms. The objective of this study was to observe the transformation characteristics in detail by continuously measuring the permeability changes with depth on various snow/ice cores.

\section{EXPERIMENTAL PROGEDURES}

The shallow-ice core samples were obtained from three Antarctic sites: Byrd Surface Camp $\left(80^{\circ} \mathrm{S}, 120^{\circ} \mathrm{W}\right), \mathrm{G} 6$ $\left(73^{\circ} \mathrm{S}, 40^{\circ} \mathrm{E}\right)$ and $\mathrm{S} 25\left(69^{\circ} \mathrm{S}, 41^{\circ} \mathrm{E}\right)$. Discrete depth samples were also obtained from six sites in Greenland: $\mathrm{J}$ $\left(67^{\circ} \mathrm{N}, 46^{\circ} \mathrm{W}\right)$; and $\mathrm{A}\left(71^{\circ} \mathrm{N}, 36^{\circ} \mathrm{W}\right), \mathrm{B}\left(71^{\circ} \mathrm{N}, 37^{\circ} \mathrm{W}\right)$, D $\left(71^{\circ} \mathrm{N}, 40^{\circ} \mathrm{W}\right), \mathrm{E}\left(72^{\circ} \mathrm{N}, 36^{\circ} \mathrm{W}\right)$ and $\mathrm{G}\left(71^{\circ} \mathrm{N}\right.$, $\left.36^{\circ} \mathrm{W}\right)$. Site $\mathrm{J}$ is located in a percolation zone; consequently the core contains a considerable volume of melt layers equal to about $20 \%$ of its length (Kameda and others, personal communication). Drilling-site environments for the other cores measured are located in dry-snow zones of the ice sheets. A qualitative measure of permeability was made by using a continuous airsucking system which was applied to a microtomed plane of each core sample. In this fashion, each data point was resolved in $1.6 \mathrm{~cm}$ increments. Accurate density determinations were made using the volumetric method on small rectangular-shaped pieces of the sample $\left(20-25 \mathrm{~cm}^{3}\right.$ each) prepared from the Byrd and G6 ice cores. All laboratory experiments were conducted in a cold room at $-10^{\circ}$ to $-18^{\circ} \mathrm{C}$. Results were corrected to a standard temperature.

\section{EXPERIMENTAL RESULTS}

Experimental results of permeability measurements indicate that the transformation from firn to ice is discontinuous and takes place within a specific depth zone where permeable layers are sandwiched between impermeable layers, as was observed on the ice core from Siple Station, Antarctica (Schwander and Stauffer, 1984). This transformation-zone depth interval ranges from 49.9 to $56.5 \mathrm{~m}$ for the Byrd Surface Camp core (Fig. la), 69.5-77.8 $\mathrm{m}$ for the G6 core (Fig. 1b), and 36.5$48.2 \mathrm{~m}$ for the S25 core (Fig. 1c). For the impermeable layers within these identified zones, the lowest and highest density values are $0.811 \mathrm{~g} \mathrm{~cm}^{-3}$ and $0.814 \mathrm{~g} \mathrm{~cm}^{-3}$ for the Byrd core (Fig. 2a) and $0.812 \mathrm{~g} \mathrm{~cm}^{-3}$ and $0.815 \mathrm{~g} \mathrm{~cm}^{-3}$ for the $\mathrm{G} 6$ core (Fig. 2b). The site J core (with no thick ice layers) and sites A, B, D, E and G cores have pore closeoff zonal-transformational characteristics as shown in Figures 3 and 4 , respectively. The percentage of pore close-off layers in a $50 \mathrm{~cm}$-long core increment was defined as pore close-off ratio (PCR) and is shown in Figure $5 \mathrm{a}$ and $\mathrm{b}$. 
Langway and others: Transformation of polar firn to ice
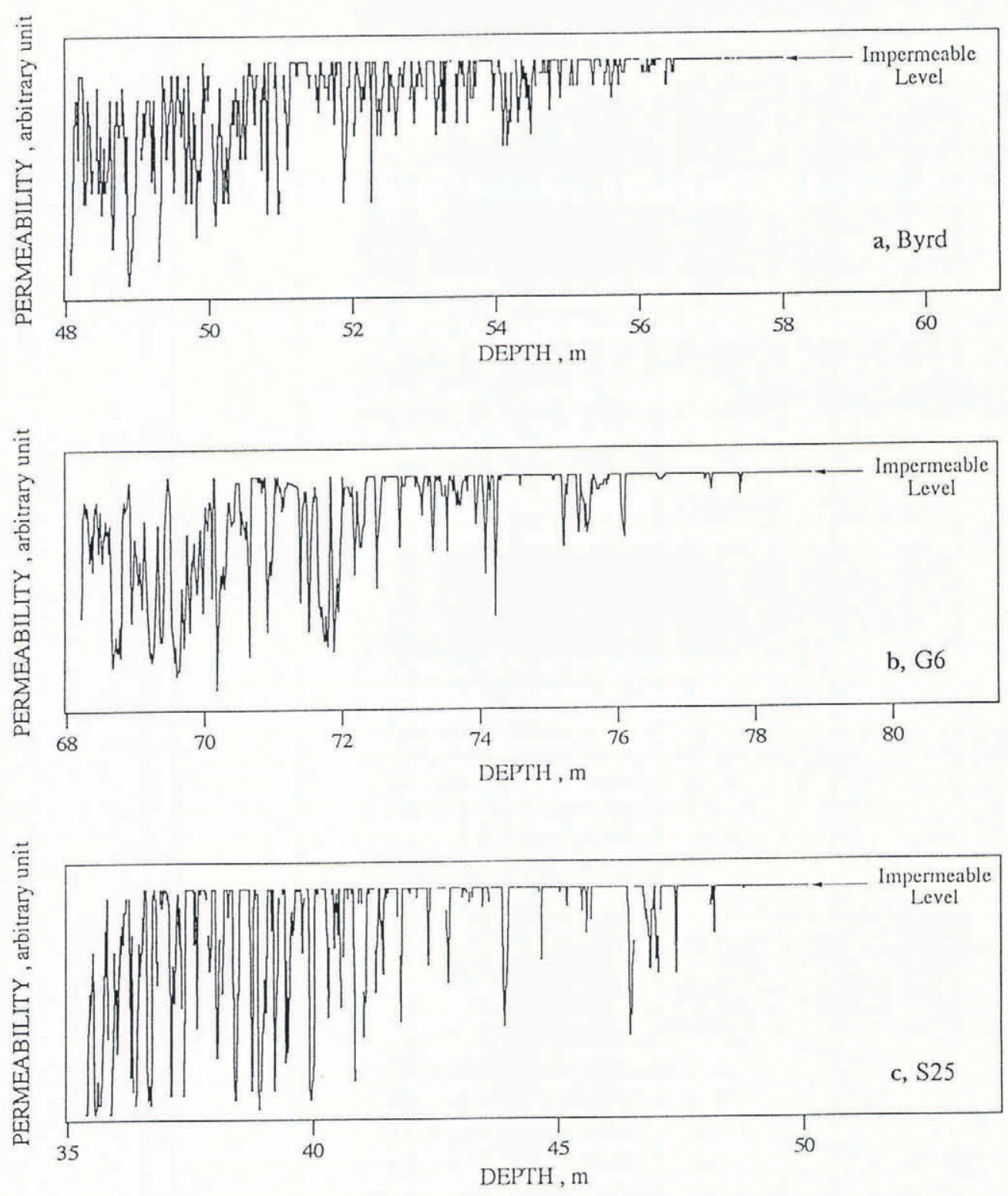

Fig. 1. Continuous permeability measurements on samples from a, Byrd Surface Camp, Antarctica; $b$, G6, Antarctica; $c$, S25, Antarctica.
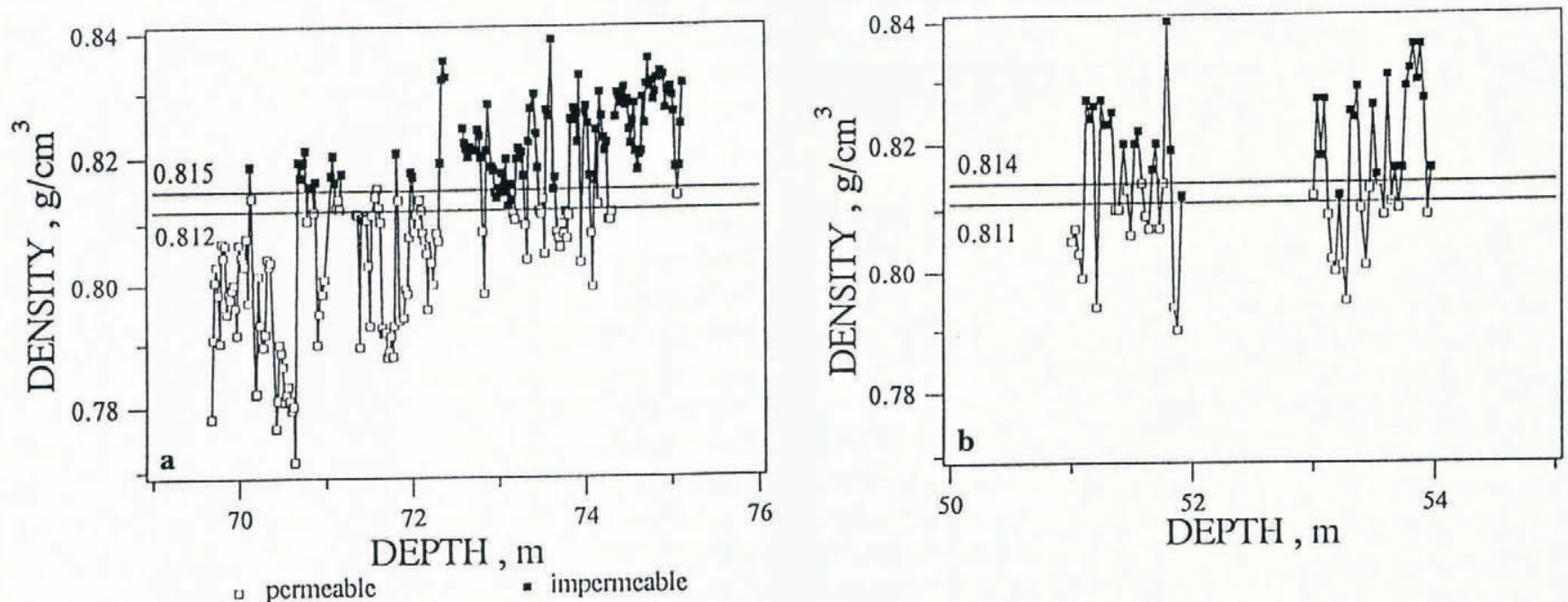

Fig. 2. Precision density variations in the permeable/impermeable layer sequences at a, Byrd Surface Camp, Antarctica; $b$, G6, Antarctica. $\square$, permeable; $\mathbf{\square}$, impermeable. 


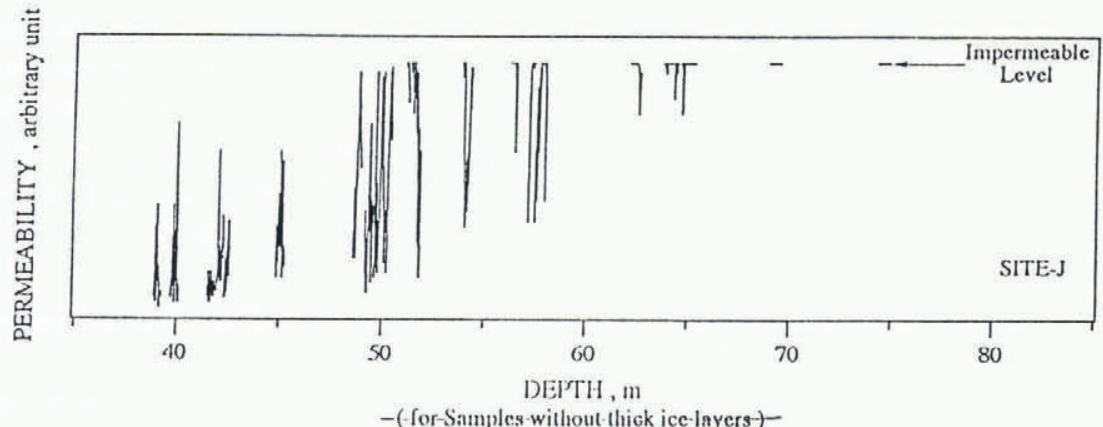

Fig. 3. Permeability measurements on ice-core samples without thick (i.e. $>1 \mathrm{~cm}$ ) ice lens/layers from site $\mathcal{F}$, Greenland.
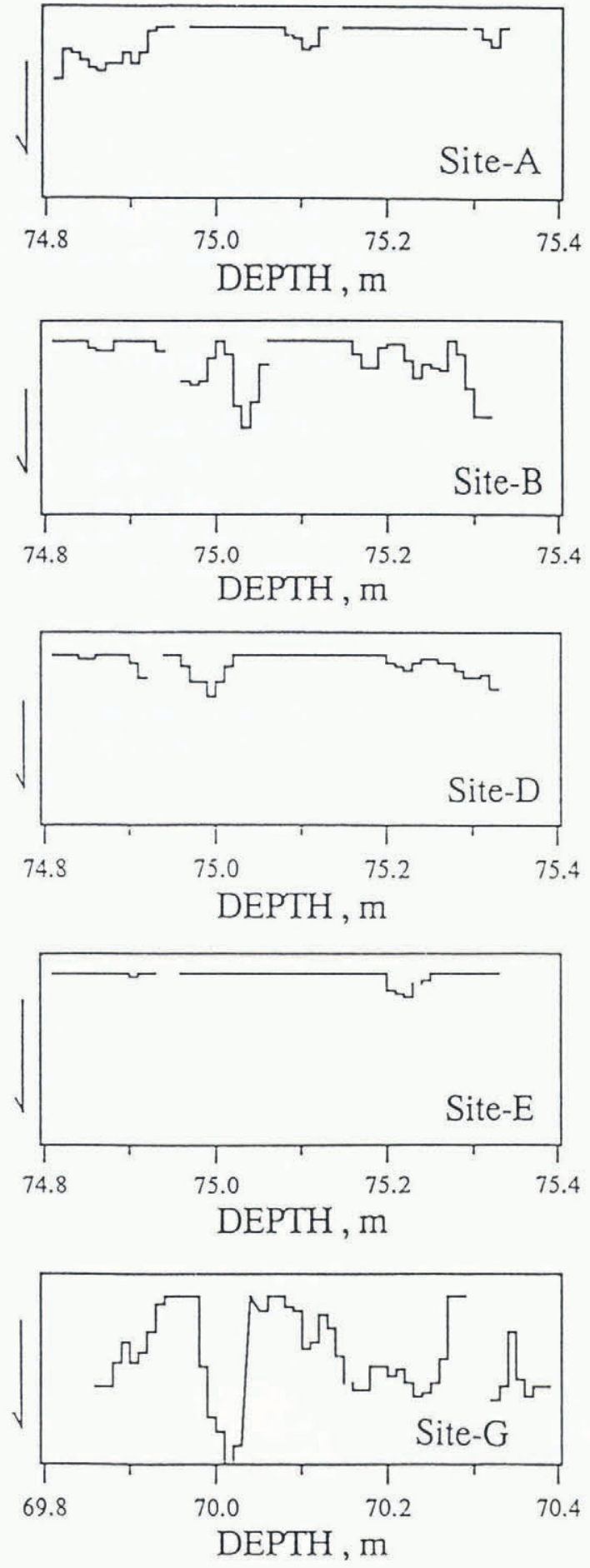

Fig. 4. Permeability measurements on ice-core samples from sites $A, B, D, E$ and $G$, Greenland.
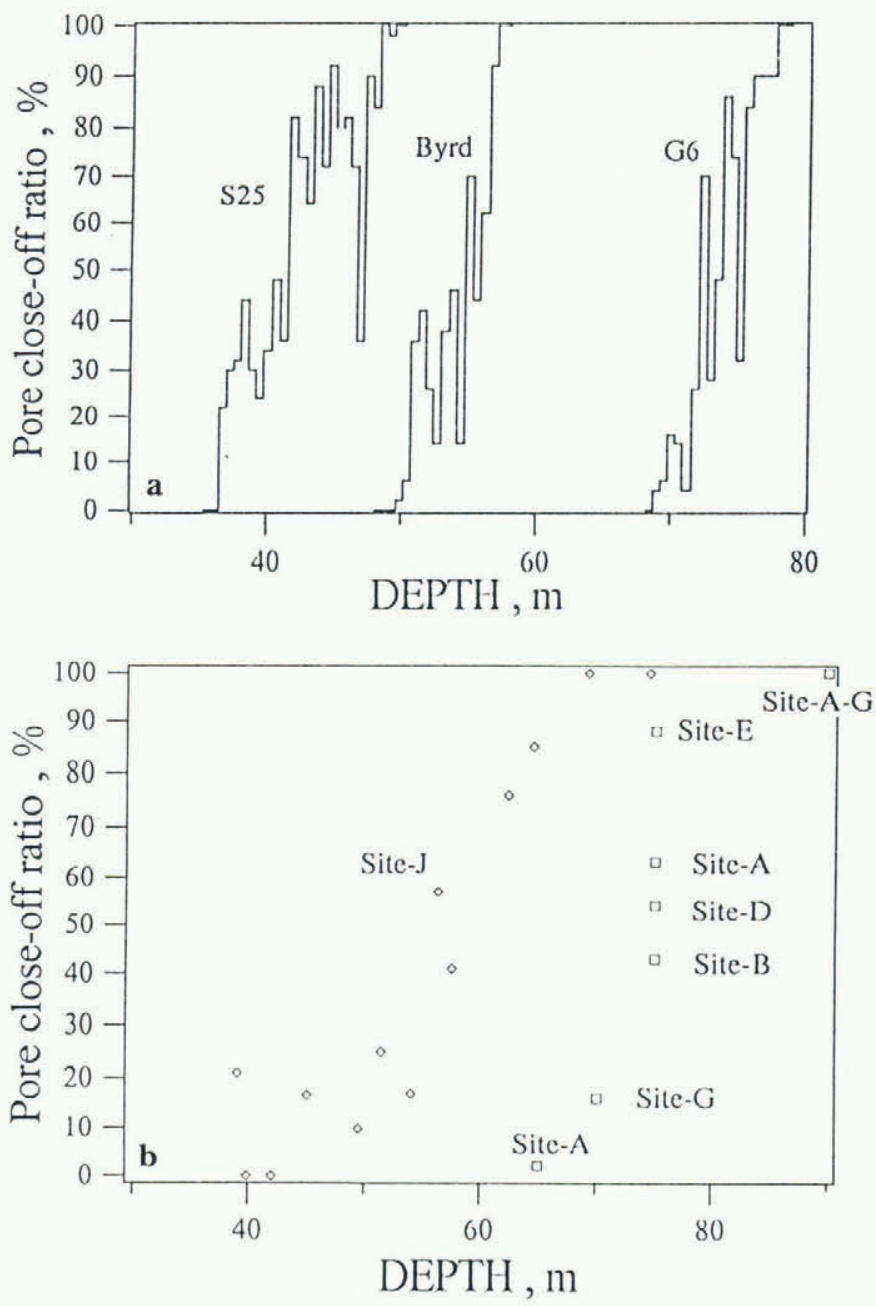

Fig. 5. Pore close-off ratio (PCR) curves for $S 25$, Byrd and $G 6$, Antarctica, and for site $\mathcal{J}$ and sites $A, B, D, E$ and $G$, Greenland.

\section{DISCUSSIONS}

The overburden pressure at the middle depth of the transition zone (a depth for the 50\% PCR) was calculated by using the bulk-density profile measured for each core (Clausen and others, 1988; Shoji and Fujii, 1991; Shoji and others, 1991; personal communication from $\mathrm{O}$. Watanabe) and plotted against mean annual surface temperature (Fig. 6). The pressure values calculated are nearly constant between 3.1 and 4.5 bar. 


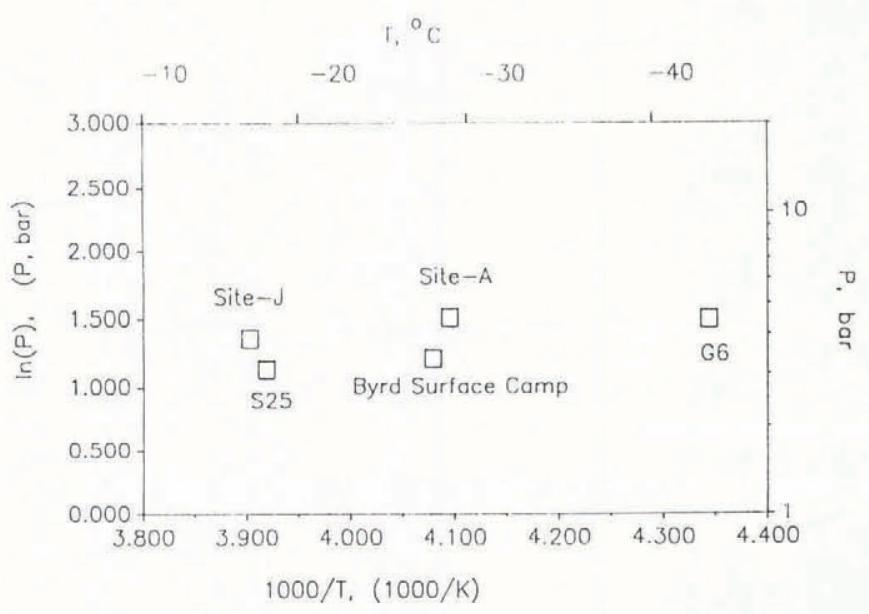

Fig. 6. Overburden-pressure values $(P)$ at various depths for pore close-off.

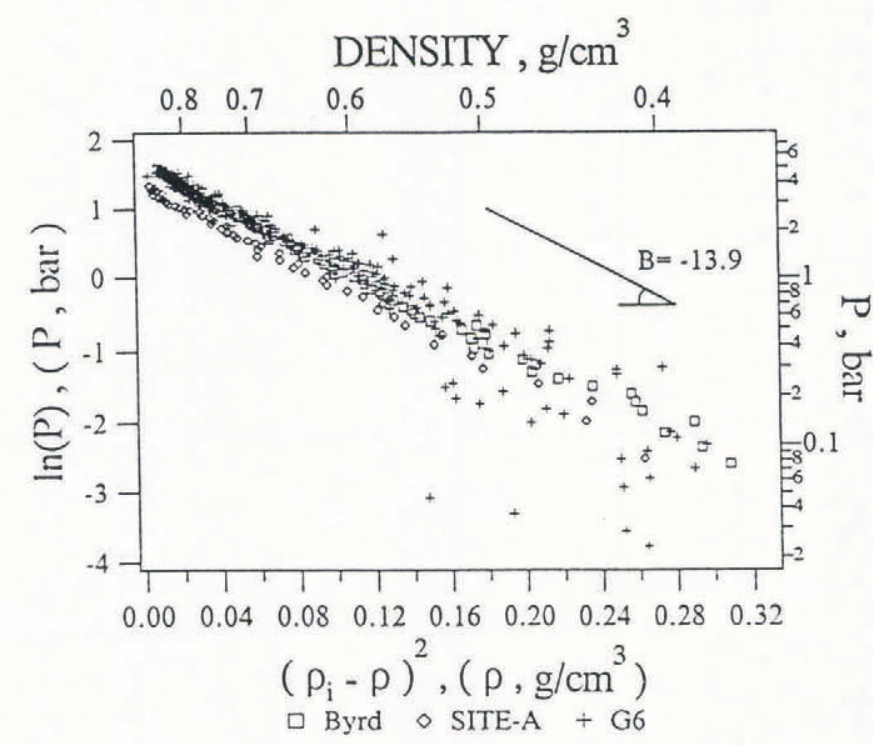

Fig. 7. Relationships between overburden pressure and density at Byrd, G6 and site A.
However, the data points for the Greenland cores seem to be slightly higher than those for the Antarctic cores. This determination results in the derivation of the following empirical equation to express the relationship between density and the overburden pressure from the surface to the pore close-off depth,

$$
P=A \exp \left(B\left(\rho_{i}-\rho\right)^{2}\right)
$$

where $P$ is overburden pressure (bar) and $\rho_{i}$ and $\rho$ are density values $\left(\mathrm{g} \mathrm{cm}^{-3}\right)$ of pure ice and firn, respectively. $A$ and $B$ are constants. The value of $\mathrm{B}$ is close to -13.9 as shown in Figure 7.

\section{REFERENCES}

Clausen, H. B., N. S. Gundestrup, S.J. Johnsen, R. Bindschadler and J. Zwally. 1988. Glaciological investigations in the Crête area, central Greenland: a search for a new deep-drilling site. Ann. Glaciol., 10, 1015.

Schwander, J. and B. Stauffer. 1984. Age difference between polar ice and the air trapped in its bubbles. Nature, 311(5981), 45-47.

Shoji, H. and Y. Fujii. 1991. Preliminary study of the G6, Antarctic ice core. (Abstract.) Proceedings of the NIPR Symposium on Polar Meteorology and Glaciology 4, 135.

Shoji, H., H.B. Clausen and T. Kameda. 1991. Accumulation rate at Site-J and Dye-2, Greenland. Bull. Glacier Res. 9, 85-88

The accuracy of references in the text and in this list is the responsibility of the authors, to whom queries should be addressed. 